\title{
Tetraphenylporphyrin Lanthanide Complexes as New Optical Sensor Media for Oxygen Determination
}

\author{
Elena G. Ermolina ${ }^{1}$, Rimma T. Kuznetsova ${ }^{1}$, Tat'yana A. Solodovaa ${ }^{1}$, Tat'yana N. Kopylova $^{1}$, Nikolay N. \\ Semenishyn ${ }^{2}$, Natal'ya V. Rusakova ${ }^{2}$, Tat'yana A. Ageevaa $^{3}$, Sophia A. Kuvshinova ${ }^{3}$ \\ Tomsk State University, 634050, Lenin av., 36, Tomsk, Russia \\ E-mail: erm.phch@gmail.com, kuznetrt@mail.ru \\ ${ }^{2}$ A. V. Bogatsky Physico-Chemical Institute, NAS of Ukraine,65080, Lustdorf road, 78, Odessa, \\ Ukraine \\ ${ }^{3}$ Ivanovo State University of Chemical Technology, 153000, Engels av., 7, Ivanovo, Russia
}

\begin{abstract}
:
We report on the phosphorescence emission spectra of the complexes of lutetium(III) and gadolinium(III) with tetraphenylporphyrin in thin films of polytretbutylmethacrylate, polystyrene, polyvinylchloride, polycarbonate, methyl- and diacetylcellulose. The complexes were photoexcited at $420 \mathrm{~nm}$ and display room temperature phosphorescene (with a peak at $780 \mathrm{~nm}$ ) that is quenched by molecular oxygen at room temperature. This effect was first exploited for these substances to optically sense oxygen. The response time is about $1.0 \mathrm{~s}$, and the detection limit is $0.05 \%$ of oxygen in the gas.
\end{abstract}

Key words: oxygen sensor, lanthanide, porphyrin, phosphorescence, matrix influence.

\section{Introduction}

Methods of determining oxygen in gas mixtures are widely used. In the last few years, the optical direction of oxygen sensing based on quenching of organic dye luminescence by $\mathrm{O}_{2}$ molecules has actively been developed. The active search for the compounds possessing high sensitivity to oxygen is on among metalporphyrins, transition metal complexes and polycyclic aromatic hydrocarbons [1, 2]. Platinum and palladium porphyrins are promising materials [3]. Lanthanide complexes with tetraphenylporphyrin are more economically available than platinum and palladium complexes. In present work these complexes are used for the first time as agents for optical oxygen sensing.

\section{Experimental Details}

The tetraphenylporphyrin complexes with lanthanide ions $\mathrm{Lu}(\mathrm{III})$ and $\mathrm{Gd}(\mathrm{III})$ and $\mathrm{Cl}^{-}$anion as axial ligand (fig. 1) were investigated in ethanol solutions, polymeric films of different compositions, and films based on methyl-(MC) and diacetylcellulose (DAC). Polyvinylchloride (PVC), polycarbonate (PC) and copolymers of tert-butylmethacrylate or styrene with propylmethacrylate, comprising 15 or $25 \%$ of octa(propylmethacrylate) polyhedral oligomerous silsesquioxane (POSS) as a lateral substituent were used (tBu-POSS, St-POSS) (fig. 2).

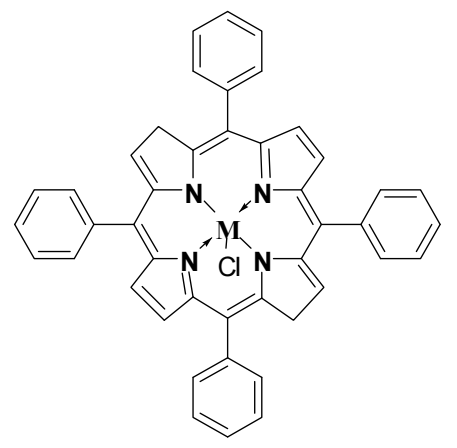

Fig. 1. Structure of the CIMTPP complexes with $M=L u(I I I)$ or $G d(I I I)$.

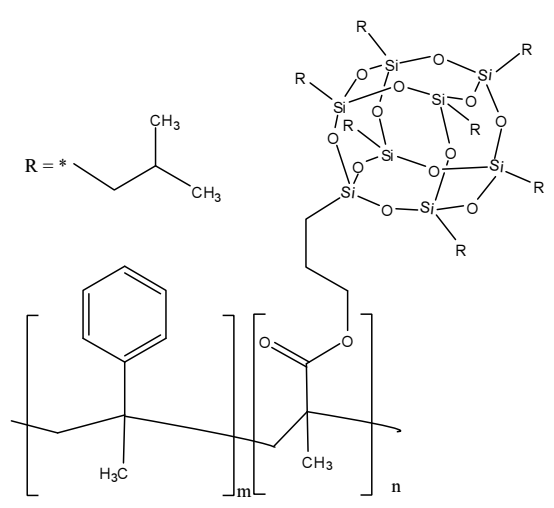

Fig. 2. Structure of poly[(propylmethacryl-heptaiso-butyl-POSS)-co-(styrene)] (St-POSS). 
The sensor properties of polymeric films with incorporated complexes were investigated on a setup [4] consisting of SM2203 spectrofluorimeter, UFPGS-4 device intended for generating gas mixture flow with error $\leq 2 \%$, a gas cell with the examined sample put in the cell block of the spectrofluorimeter, and a personal computer.

\section{Sensor Abilities}

The spectral and luminescent properties of the examined compounds in ethanol solutions are presented in Table 1. From the Table it follows that the substitution of the zinc ion by a heavy ion resulted in only insignificant displacement of the absorption and luminescence spectra. Incorporation of the heavy ion changes the conventional photophysics of the molecule: the quantum radiation yield decreases from the $S_{1}$ state and increases from the $T_{1}$-state. This is caused by the intensified intercombination conversion, increased population of the lower

Table 1. Spectral and luminescent properties of ethanol solutions of the examined complexes at $\lambda_{\text {exc }}=555 \mathrm{~nm}$. Here * indicates the degassed solution.

\begin{tabular}{|c|c|c|c|c|c|c|c|c|c|c|}
\hline \multirow{3}{*}{ Comp. } & \multirow{3}{*}{ Abs. } & \multicolumn{4}{|c|}{ Fluorescence } & \multicolumn{5}{|c|}{ Phosphorescence } \\
\hline & & \multicolumn{2}{|c|}{$298 \mathrm{~K}$} & \multicolumn{2}{|c|}{$80 \mathrm{~K}$} & \multicolumn{2}{|c|}{$298 \mathrm{~K}$} & \multicolumn{3}{|c|}{$80 \mathrm{~K}$} \\
\hline & & $\lambda, \mathrm{nm}$ & $\varphi$ & $\lambda, \mathrm{nm}$ & $\varphi$ & $\lambda, \mathrm{nm}$ & $\varphi$ & $\lambda, \mathrm{nm}$ & $\varphi$ & $\begin{array}{c}\mathrm{T}, \\
\mathrm{ms}\end{array}$ \\
\hline ZnTPP & $\begin{array}{l}421 \\
557 \\
597\end{array}$ & $\begin{array}{l}602 \\
656\end{array}$ & 0.030 & $\begin{array}{l}597 \\
653\end{array}$ & 0.055 & - & - & 781 & 0.015 & 20.5 \\
\hline CILUTPP & $\begin{array}{l}419 \\
550 \\
587\end{array}$ & $\begin{array}{l}600 \\
644\end{array}$ & $2.8 \cdot 10^{-3}$ & $\begin{array}{l}593 \\
643\end{array}$ & $5.2 \cdot 10^{-3}$ & - & - & 761 & 0.395 & 2.9 \\
\hline CIGdTPP & $\begin{array}{l}422 \\
554 \\
591\end{array}$ & $\begin{array}{l}648 \\
716\end{array}$ & $1.2 \cdot 10^{-3}$ & $\begin{array}{l}644 \\
711 \\
773\end{array}$ & $4.2 \cdot 10^{-3}$ & *776 & $* 1.6 \cdot 10^{-3}$ & 772 & 0.061 & 2.6 \\
\hline 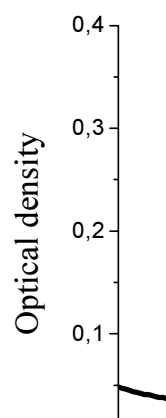 & $\begin{array}{l}1: 1 \\
: \\
: \\
\vdots \\
\vdots \\
:\end{array}$ & 2 & & & 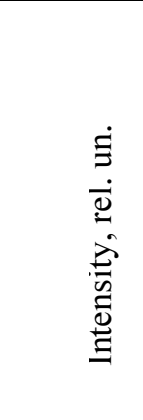 & ${ }^{4} 7$ & & $\begin{array}{ll}1 & 1 \\
1 \\
1 \\
1 \\
1 \\
1 \\
1 & 2\end{array}$ & $\begin{array}{l}1 \\
1 \\
1 \\
1\end{array}$ & \\
\hline & 400 & Wavelen & $\mathrm{nm}$ & & & $0 \longdiv { 7 }$ & $650 \quad 700$ & 750 & $800 \quad 850$ & \\
\hline
\end{tabular}

Fig. 3. Absorption spectra of CILUTPP in ethanol (curve 1) and ST-POSS 25 film (curve 2). triplet state, and increased phosphorescence lifetime. The residual phosphorescence was registered for partly deaerated ethanol solutions of the examined lanthanide compounds at room temperature (see Table 1).

A small red shift $(5 \mathrm{~nm})$ and broadening of the absorption spectrum maxima (Fig. 3) were observed for the complexes in films. The ratio of the B-band intensity to the Q-band (420 and $560 \mathrm{~nm}$, respectively) intensity was somewhat decreased. This decrease is due to a change in the microenvironment of the dye molecules in the film compared to the solution as well as due to the influence of specific interactions of electron-donor oxygen atoms of the matrix with electron-acceptor porphyrin centers by means of which the dye molecules are fixed in the matrix. The luminescence spectra of the compounds in the polymeric films and films based on methylcellulose were close to the luminescence of ethanol solutions. 


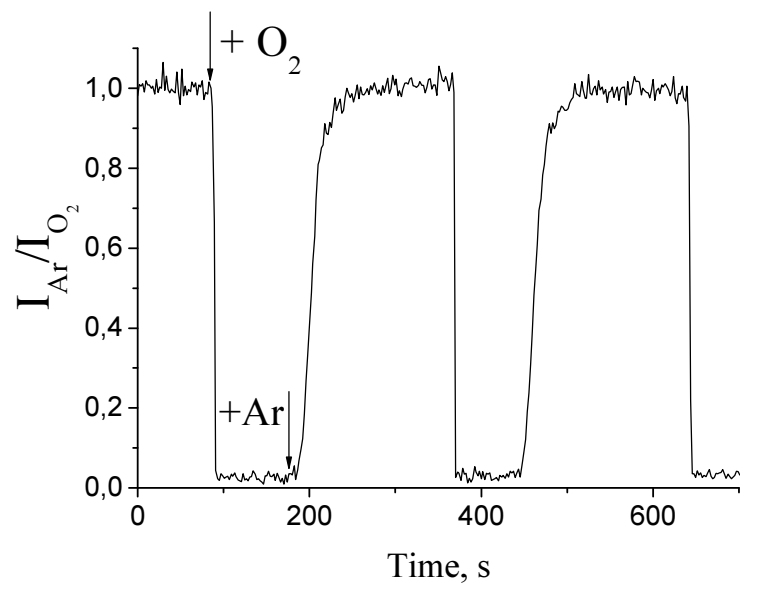

Fig. 5. Response time and changes of the phosphorescence intensity at $780 \mathrm{~nm}$ for the same film.

The main sensor characteristics are the system response time to incoming analyte, range of measurable concentrations, and primarily the sensitivity to analyte determined by the ratio $I_{0} / I_{100}$ for optical sensors, where $I_{0}$ and $I_{100}$ are the luminescence intensities for analyte concentrations of 0 and $100 \%$, respectively [3]. The sensitivity to oxygen for the indicated materials doped by CIGdTPP and CILUTPP is given in Tab. 2 with error of $5 \%$. Values of $I_{0} / I_{100}$ presented in Tab. 2 allowed the presence or absence of oxygen in the measuring chamber to be reliably detected; moreover, for CILUTPP in the film based on methylcellulose, $I_{0} / I_{100}=40$ was close to the best results obtained in [3] for octoethylporphyrin complexes with palladium and platinum in organically modified sol-gel films. The best result was obtained for samples with CILUTPP in the poured film based on methylcellulose and in DAC-film. This can be explained by the large phosphorescence yield of this compound and, presumably, by the optimal relationship between the film permeability and thickness in this case. The materials obtained are distinguished by short enough response time of about $1.0 \mathrm{~s}$.

\section{References}

[1] Y. Amao, Microchimica Acta 143, 1-12 (2003); doi: 10.1007/s00604-003-0037-x

[2] B.J. Basu, A. Thirumurugan, A.R. Dinesh, C. Anandan, K.S. Rajam, Sensors Actuators B 104, 15-22 (2005); doi: 10.1016/j.snb.2004.04.092.

[3] X. Wang, H. Chen, Y. Zhao, X. Chen, X. Wang, Trends in Analitical Chemistry 29, 319-338 (2010); doi: 10.1016/j.trac.2010.01.004.

[4] E.G.Ermolina, R.T.Kuznetsova, T.A.Solodova, E.N.Tel'monov, T.N.Kopylova, G.V.Mayer, N.N.Semenishyn, N.V.Rusakova, Yu.V.Korovin.
Tab. 2: Sensitivity to oxygen $\left(I_{0} / l_{100}\right)$ of the indicated materials doped by CIMTPP

\begin{tabular}{|c|c|c|}
\hline Compound & Film material & $I_{0} / I_{100}$ \\
\hline \multirow{4}{*}{ CIGdTPP } & tBu-POSS15 & 4.2 \\
\cline { 2 - 3 } & St-POSS15 & 2.9 \\
\cline { 2 - 3 } & St-POSS25 & 2.6 \\
\cline { 2 - 3 } & PVC & 3.0 \\
\cline { 2 - 3 } & PC & 2.4 \\
\cline { 2 - 3 } & DC (spin-coating) & 3.3 \\
\cline { 2 - 3 } & MC (poured) & 5.1 \\
\hline \multirow{5}{*}{ CILuTPP } & tBu-POSS15 & 4.9 \\
\cline { 2 - 3 } & St-POSS15 & 3.5 \\
\cline { 2 - 3 } & St-POSS25 & 7.7 \\
\cline { 2 - 3 } & DAC & 17.5 \\
\cline { 2 - 3 } & MC (spin-coating) & 9.3 \\
\cline { 2 - 3 } & MC (poured) & 40.0 \\
\hline
\end{tabular}

\section{Conclusions}

The examined CILUTPP and CIGdTPP complexes possess intensive phosphorescence due to high interconversion yield caused by the effect of the internal heavy atom. The sensitivity to oxygen of solid state materials doped by the indicated complexes has been investigated for the first time. The sensitivity of polymeric films and films based on methylcellulose comprising the indicated complexes as sensory agents to oxygen reached 40 . This allows to consider CILUTPP and CIGdTPP as new available agents for optical oxygen sensing.

\section{Aknowledgements}

This work was supported by grant of RFBR No.12-02-90008-Bel_a and by Presidential Scholarship PS-6667.2013.4.

Dyes and Pigments 97, 209-214 (2013); doi: 10.1016/j.dyepig.2012.12.018. 